\title{
Neuronavigation in minimally invasive spine surgery
}

\author{
*Ziev B. Moses, M.D., ${ }^{1}$ Rory R. Mayer, M.D., ${ }^{2}$ Benjamin A. Strickland, B.A., ${ }^{2}$ \\ Ryan M. Kretzer, M.D., ${ }^{3}$ Jean-Paul Wolinsky, M.D., ${ }^{3}$ Ziya L. Gokaslan, M.D., ${ }^{3}$ \\ AND Ali A. BAAJ, M.D. ${ }^{4}$ \\ ${ }^{1}$ Departments of Neurosurgery, Brigham and Women's Hospital and Boston Children's Hospital, Harvard \\ Medical School, Boston, Massachusetts; ${ }^{2}$ Departments of Neurosurgery, Baylor College of Medicine and The \\ University of Texas MD Anderson Cancer Center, Houston, Texas; ${ }^{3}$ Department of Neurosurgery, Johns \\ Hopkins School of Medicine, Baltimore, Maryland; and ${ }^{4}$ Division of Neurosurgery, The University of Arizona, \\ Tuscon, Arizona
}

\begin{abstract}
Object. Parallel advancements in image guidance technology and minimal access techniques continue to push the frontiers of minimally invasive spine surgery (MISS). While traditional intraoperative imaging remains widely used, newer platforms, such as 3D-fluoroscopy, cone-beam CT, and intraoperative CT/MRI, have enabled safer, more accurate instrumentation placement with less radiation exposure to the surgeon. The goal of this work is to provide a review of the current uses of advanced image guidance in MISS.

Methods. The authors searched PubMed for relevant articles concerning MISS, with particular attention to the use of image-guidance platforms. Pertinent studies published in English were further compiled and characterized into relevant analyses of MISS of the cervical, thoracic, and lumbosacral regions.

Results. Fifty-two studies were included for review. These describe the use of the iso-C system for 3D navigation during C1-2 transarticular screw placement, the use of endoscopic techniques in the cervical spine, and the role of navigation guidance at the occipital-cervical junction. The authors discuss the evolving literature concerning neuronavigation during pedicle screw placement in the thoracic and lumbar spine in the setting of infection, trauma, and deformity surgery and review the use of image guidance in transsacral approaches.

Conclusions. Refinements in image-guidance technologies and minimal access techniques have converged on spinal pathology, affording patients the ability to undergo safe, accurate operations without the associated morbidities of conventional approaches. While percutaneous transpedicular screw placement is among the most common procedures to benefit from navigation, other areas of spine surgery can benefit from advances in neuronavigation and further growth in the field of image-guided MISS is anticipated.

(http://thejns.org/doi/abs/10.3171/2013.5.FOCUS13150)
\end{abstract}

\author{
KEY WORDS • minimally invasive spine surgery $\quad$ neuronavigation $\bullet$ \\ image guidance
}

$\mathrm{P}$ ARALLEL advancements in image-guidance technology and minimal access techniques continue to push the frontiers of minimally invasive spine surgery (MISS). While traditional intraoperative imaging (radiography, C-arm fluoroscopy) remains widely used, newer platforms, such as 3D-fluoroscopy, cone-beam CT, and intraoperative CT/MRI, have enabled safer, more accurate instrumentation placement with less radiation exposure to the surgeon and operative staff. The advent of such techniques, including cone-beam CT, boasts near real-time image reconstruction in all planes and provides higher

\footnotetext{
Abbreviations used in this paper: $\mathrm{ACDF}=$ anterior cervical discectomy and fusion; BFRS = biplane fluoroscopy-guided robot system; iCT $=$ intraoperative CT; iMRI = intraoperative MRI; MISS = minimally invasive spine surgery; OCJ = occipitocervical junction; $\mathrm{TLIF}=$ transforaminal lumbar interbody fusion .

* Drs. Moses and Mayer contributed equally to this work.
}

anatomical visualization quality compared with traditional intraoperative imaging techniques. ${ }^{27}$ These technologies are particularly exciting in the field of MISS where exposure to ionizing radiation is not insignificant. ${ }^{31,45}$ The goal of this work is to provide a review of the current uses of advanced image-guidance in MISS.

\section{Image Guidance in Cervical MISS}

The cervical region presents unique anatomical challenges that make advanced image guidance attractive. First, the proximity of the vertebral arteries and neural elements to the bony anatomy in this region makes surgical precision of paramount importance, most particularly in the high cervical spine region. Vertebral artery injury is a major reported complication of C1-2 transarticular screw placement, reported in as many as $4.1 \%$ of procedures. ${ }^{24}$ 
A cadaveric study assessing the feasibility of imageguided MISS for posterior cervical screw placement was conducted using the Iso-C system (Siremobil Iso-C 3D, Siemens Medical Solutions), which allows for 3D navigation. ${ }^{10}$ Forty-two 4.0 -mm-diameter screws were placed at the C1-2 transarticular, C3-6 lateral mass, and C-7 transpedicular locations. This resulted in an accurate placement rate of $97.6 \%$, with only one transpedicular screw at C-7 having a minor cortical breech. The remaining 41 screws were accurately placed, without evidence of transverse foramen, neural foramen, or facet joint violation. Similarly, in a small clinical study of translaminar screw placement at $\mathrm{C}-2$, where ventral spinal canal violations have been reported, 3D fluoroscopy-navigated MISS was shown to be safe and effective, without occurrence of dorsal or ventral breeches. ${ }^{30}$ Similarly, Ishikawa et al. report decreased complication rates in cervical pedicle screw placement with the use of 3D fluoroscopy-based navigation. ${ }^{15}$ In a recent cadaveric study of lower cervical spine pedicle screw placement, Tian and colleagues evaluated CT-based navigation and Iso-C 3D navigation systems relative to fluoroscopic assistance and virtual fluoroscopy for screw placement. In the CT-based and Iso-C 3D systems, no screws were placed in a "poor" location, with more than $1 \mathrm{~mm}$ of the screw penetrating into the isthmus. In contrast, $12.5 \%-17.9 \%$ of attempts were placed in "poor" locations without computer-based navigation. ${ }^{43}$ These findings are consistent with reported transarticular and translaminar breeches of $15 \%$ and $18 \%$, respectively, in nonnavigated procedures. ${ }^{7,48}$

Another area of expanding interest is in the minimally invasive treatment of cervical degenerative disease. One of the most common procedures performed for this condition is $\mathrm{ACDF}^{25}$ While not generally considered a MISS procedure, variations, including the fully endoscopic ACDF, use minimal access techniques and have been shown to be associated with diminished morbidity compared with conventional ACDF. ${ }^{33,51}$ Simultaneously, other minimal approaches have been developed in light of the various established disadvantages associated with ACDF, including adjacent-level disease, immobility, and dysphagia. Both anterior and posterior cervical microforaminotomies are MISS procedures aimed at decompressing the neural foramina by targeting the pathology and avoiding removal of bony anatomy that may compromise spinal stability. ${ }^{5,18}$ However, to date, a paucity of studies exists comparing the risks of navigated versus nonnavigated minimal access approaches for cervical degenerative disease. One recent technical report detailing modified transcorporeal anterior cervical microforaminotomy with $\mathrm{O}$-arm based navigation (Medtronic Sofamor Danek) noted smaller skin incisions and drill hole sizes (Fig. 1). ${ }^{18}$ In addition, radiation exposure to the patient and surgeon were limited in contrast with the typically increased exposure with the use of continuous intraoperative fluoroscopy. The authors noted increased confidence in localizing the correct surgical level and finding the appropriate surgical margin for decompression.

Advanced image guidance is of particular utility at the occipital-cervical junction (OCJ). In 2007, Wolinsky and colleagues described the use of frameless stereotactic navigation and isocentric $\mathrm{C}$-arm fluoroscopy to guide the

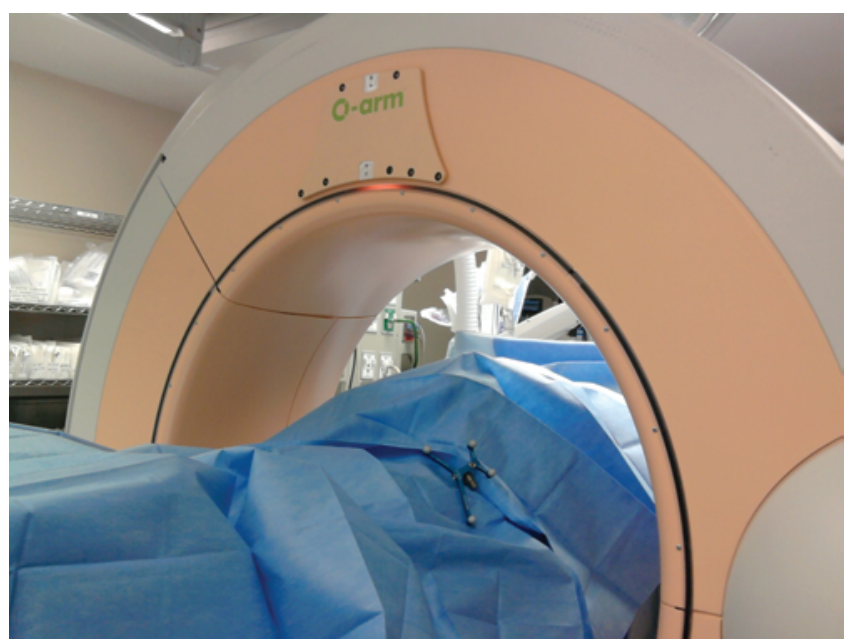

FIG. 1. Intraoperative O-arm (Medtronic Sofamor Danek) for neuronavigation.

surgical trajectory during transcervical odontoidectomy for basilar invagination. ${ }^{49}$ The efficacy of this technique, combining advances in endoscopy, tubular retraction, and frameless stereotaxy, has been further demonstrated in a follow-up series of 15 patients. All patients demonstrated long-term improvement in myelopathy and avoided some of the morbidity of transoral surgery. ${ }^{3}$ In parallel, a recent technical paper by Hsu et al. expands upon this imageguided approach to cervical pathology, describing the use of frameless stereotactic navigation during endoscopic, transcervical resection of a chordoma for accurate tumor localization, identification of the vertebral arteries, and delineation of the dural sac. ${ }^{14}$ Leng et al. described the utility of a preoperative CT angiogram of the cervical spine uploaded to a frameless stereotactic neuronavigation system (BrainLAB) to guide and facilitate the resection of pathology and help in the delineation of important vascular anatomy. ${ }^{22}$ During posterior cervical fusion, C-2 laminar screws are now being used to provide rigid fixation with minimal risk to the vertebral artery. Nottmeier and colleagues report on the placement of 4-mm C-2 laminar screws in 8 patients undergoing posterior cervical fusion using 3D fluoroscopy-based image guidance. All 13 C-2 laminar screws evaluated by means of postoperative CT were found in their target position with no breach of the spinal canal. ${ }^{26}$

A 2001 feasibility study by Kaibara and colleagues detailed the use of intraoperative MRI as an aid to transoral resection of cervicomedullary junction lesions. ${ }^{16}$ With more recent advancements in neuronavigation, this concept was evaluated in more detail in a 2012 study by Dhaliwal et al. ${ }^{4}$ In their study, 22 patients underwent surgery with the aid of neuronavigation and intraoperative MRI for the treatment of ventral craniovertebral junction disease with acceptable and expected postoperative outcomes. The authors detail 3 principal benefits of neuronavigation/iMRI-assessment of extent of resection, confirmation of regional anatomy, and detailing of lesion borders. ${ }^{2,4}$ Several other studies have described the use of iMRI to accurately target and fenestrate cervical, thoracic, and terminal ventricle region intradural cysts. ${ }^{40-42}$ 


\section{Neuronavigation in minimally invasive spine surgery}

One limitation of image guidance at the OCJ has been due to the challenge of stabilizing the reference arc to the dorsal bony anatomy during instrumentation. For anterior approaches, Hott et al. and Summers et al. described the placement of the reference arc on the headholder in patients undergoing 3D image-guided odontoid screw placement. ${ }^{12,39}$ This same concept for reference arc fixation has now been applied during image-guided placement of posterior OCJ instrumentation. Using this technique, Nottmeier and colleagues were able to accurately place screws at the occiput and the C-1 and C-2 levels without the need for reregistration. ${ }^{27}$

\section{Image Guidance in Thoracic MISS}

The thoracic spine is intimately involved with vital structures, such as the aorta, vena cava, and lung parenchyma, that make anterior approaches technically challenging. There has been limited utilization of navigation in thoracic MISS. Villavicencio et al. conducted a feasibility study of navigated kyphoplasty in 11 patients who underwent surgery with neuronavigation. ${ }^{46}$ The Iso-C system (Siemens Medical Solutions) linked with a StealthStation Treon (Medtronic) was used during the transpedicular approach. Radiation time was decreased to 41.3 seconds compared with an average of 293.2 seconds in 9 previous cases (historical comparison cohort) in which surgery was performed without isocentric fluoroscopy. Three thoracic and seven lumbar procedures were completed without complications.

Pedicle screw placement in the thoracic spine can be challenging given the often small size of the pedicles, particularly in female patients. Further, a freehand technique relies heavily on anatomical landmarks and tactile feel; thus accuracy of screw placement has a variable component related to individual surgical skill and is likely associated with a steep learning curve. ${ }^{1}$ This has led to screw misplacement rates as high as $55 \%$ in previous cadaveric studies using both anatomical landmarks and fluoroscopy without navigation; ${ }^{6}$ consequences of such misplacement include nerve root injury, hemorrhage, and spinal cord injury. ${ }^{1}$ In human studies of pedicle screw placement in the thoracic spine, stereotactic navigation led to reductions in cortical perforations and structurally significant violations. ${ }^{8,52}$ Youkilis et al. used preoperative CT images loaded onto a StealthStation to navigate placement of 266 thoracic pedicle screws in 65 patients with an overall cortical perforation rate of $8.5 \% .{ }^{31}$ Han et al. used a similar methodology for navigation assistance with BrainLAB and reported $4.35 \%$ of 92 pedicle screws had Grade II (< $2 \mathrm{~mm}$ ) perforations. ${ }^{8}$ Further, Allam et al. demonstrate the superiority of 3D-based navigation technique in pedicle screw placement with an accuracy of $99 \%$ as opposed to the free-hand technique with an accuracy of $89 \% .1$

While navigation for thoracic pedicle screw placement has been explored for many years, only recently has its use been examined in a minimal access approach. Holly et al. explored a percutaneous navigated approach for thoracic pedicle screw placement. ${ }^{11}$ Ninety-four percutaneous screws were placed in a cadaveric study with assistance from the Iso-C system (Siemens Medical Solutions) linked to a StealthStation Treon. Overall, 94.7\% of screws were accurately placed into pedicles with an average diameter of $6 \mathrm{~mm}$. The 5 pedicles in which a wall violation occurred had a mean diameter of $4.6 \mathrm{~mm}$, which is significantly narrower than common lumbar pedicle diameters.

In addition to providing fixation for degenerative disease, infection, and oncology, percutaneous navigated pedicle screw placement in the thoracic region has also been investigated in the context of spinal trauma (Fig. 2). A report by Kakarla et al. described the use of navigated percutaneous thoracic pedicle screw fixation in 6 patients presenting to their institution with unstable spine fractures. ${ }^{17}$ The authors used the Iso-C system (Siremobil Iso-C 3D, Siemens Medical Solutions), and no procedures were converted to an open approach. A total of 37 pedicle screws were placed, with Grade II misplacement (cortical violation of less than $2 \mathrm{~mm}$ ) occurring $16 \%$ of the time and Grade III (cortical violation beyond $2 \mathrm{~mm}$ ) in $3 \%$. No patients had neurological complications as a result of screw misplacement. Neuronavigation has also been shown useful in the trauma setting with $\mathrm{O}$-arm generation of 3D CT images, allowing for surgical assessment of spinal alignment, accuracy of reduction, and canal decompression. Further, it reduces surgeon radiation exposure, and with decreased incidence of screw malpositioning, patients may be spared additional surgery. ${ }^{37}$

\section{Image Guidance in Lumbosacral MISS}

A 2007 meta-analysis of freehand pedicle screw placement in the lumbar spine reported a median accuracy rate of $79.0 \% .{ }^{20}$ Further, during deformity surgery, thoracolumbar pedicle screw inaccuracy has been reported at levels as high as $30 \% .{ }^{35}$ Therefore, surgical adjuncts including fluoroscopy and image guidance have been advocated to improve the accuracy of transpedicular fixation. In parallel, minimally invasive techniques for adult deformity surgery have been advocated to decrease the significant recovery time and potential morbidity of

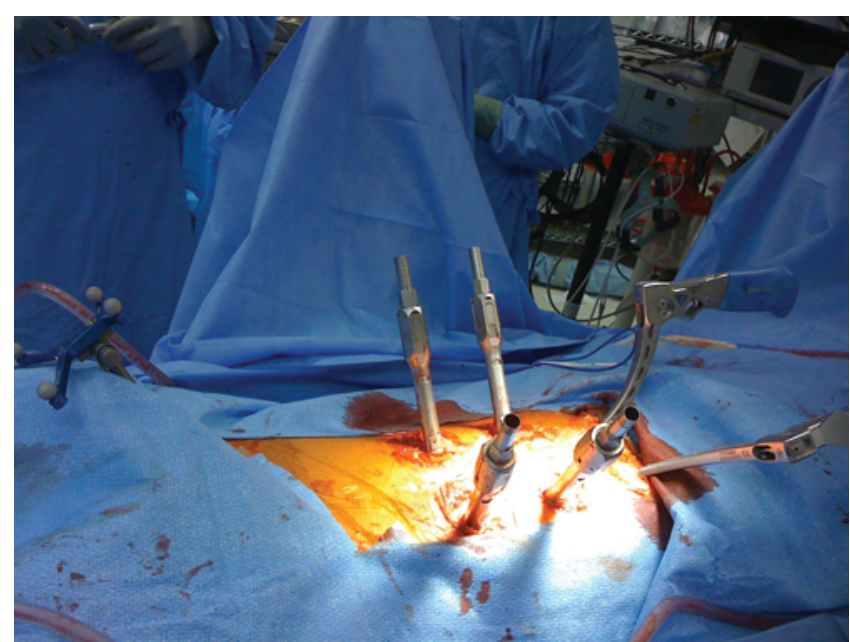

FIG. 2. Minimally invasive posterior percutaneous approach for the treatment of a traumatic T11-L1 injury. Reprinted from Clin Neurol Neurosurg 115(3), Baaj AA et al., O-Arm-based image guidance in minimally invasive spine surgery: technical note, pp 342-345, copyright 2013, with permission from Elsevier. 


\section{Z. B. Moses et al.}

these cases. Further proposed advantages of a minimally invasive approach include a decrease in the complications occurring in the elderly, medically comorbid population. In a recent study by Scheufler et al., 30 elderly individuals (age range 64-88 years) with adult degenerative scoliosis were treated by less invasive decompression and fusion using biplanar fluoroscopy or iCT-based navigation. ${ }^{35,36}$ Namely, unilateral mini-open transpedicular screw instrumentation and bilateral spinal decompression was performed in conjunction with unilateral TLIFs on the concave side of the deformity and ipsilateral posterolateral grafting. The two imaging techniques were assessed in the implantation of 415 screws. No misplacement (Grade II or greater) occurred and no revision of implants was necessary. Spinal iCT required an average of $17.5 \mathrm{~min}-$ utes for automatic registration across all segments. The average intraoperative radiation exposure to the surgeon's torso was $0.025 \mathrm{mSv}$ for single-level TLIFs utilizing fluoroscopic guidance. In contrast, radiation exposure was 0 $\mathrm{mSv}$ with $\mathrm{iCT}$ navigated instrumentation. Importantly, the study demonstrated that $\mathrm{iCT}$ provided a significantly faster time (54 minutes) to complete pedicle screw insertion than guidance with biplanar fluoroscopy (89 minutes). Spinal iCT significantly facilitated the instrumented correction of adult degenerative scoliosis, removing radiation exposure to the surgeon while enabling effective deformity reconstruction. The use of serial intraoperative frontal and lateral CT scout views (including the hips, pelvis, spine, and shoulders) provides a comprehensive means of assessing spinal alignment during instrumentation. In addition, several studies have shown that segmental fusion by minimally invasive approaches is achieved at an equal rate to that of traditional open surgical techniques..$^{35,36}$

As further evidence for the role of iCT navigation, Tormenti et al. report a pedicle wall breach rate of $1.2 \%$ in 164 thoracolumbar pedicle screws during spinal deformity surgery using intraoperative neuronavigation. ${ }^{44}$ This study demonstrates a higher degree of accuracy obtainable with $\mathrm{iCT}$ navigation relative to alternative imageguidance modalities, including Iso- $\mathrm{C} \mathrm{C}$-arm navigation and virtual fluoroscopy. And although this represents an imaging advance in the field of open spinal deformity correction, the implications for MISS are evident given the work of Scheufler and colleagues. ${ }^{36}$

Concerning sacral lesions, the use of image guidance has facilitated the development of posterior transsacral approaches. Lee and Massicotte described the use of Stealth neuronavigation in the treatment of presacral lesions via a posterior transsacral operative corridor. ${ }^{21}$ Intraoperative navigation was used to guide the trajectory of bone drilling; thereafter, standard microsurgical techniques were used. In addition, Luther et al. used a Iso-C 3D system (Siemens) registered to BrainLAB while performing AxiaLIF (axial lumbar interbody fusion), a minimally invasive approach for interbody fusion of L4-S1, in 6 patients. ${ }^{23}$ Five patients underwent discectomy and interbody fusion of one level (L5-S1), and one patient underwent a 2-level operation (L4-5, L5-S1). No complications were reported. However, the authors point out that the BrainLAB software only allows for a virtual diameter of $12 \mathrm{~mm}$, precluding accurate simulation of the transsacral screw.
Navigation has also been explored as an adjunct to the percutaneous placement of iliosacral screws, a minimal access surgery for sacroiliac instability in the setting of pelvic injury. The relative high rates of screw malposition and neurological injury following the nonnavigated percutaneous approach are attributed to wide variation in sacroiliac joint morphology and the close association of the L-5 nerve root. Therefore, navigation has the potential for increasing the accuracy and safety of this procedure. Smith et al. compared iliosacral screw malposition rates in cadavers with three different surgical navigation systems versus standard fluoroscopy. ${ }^{38}$ They achieved higher screw placement accuracy with navigation compared with nonnavigated standard fluoroscopy. Of the 3 navigation technologies used, which included FluoroNav (Medtronic), FluoroNav EM228 (Medtronic), and Iso-C 3D (Siemens), the highest accuracy was achieved using FluoroNav with a mean screw score of 1.75 . All navigation technologies were registered to a StealthStation.

\section{Present-Day Limitations}

Limitations in minimal access techniques combined with technological shortcomings present future hurdles to the continued expansion of neuronavigation in MISS. Each image-guided modality has its own particular deficiencies. In the realm of MISS that relies on preoperative CT-based imaging, the biggest limitation is in the inaccuracy between the radiographic anatomy and the surgical anatomy. A big contributor to this error is positioning differences from the time of the initial preoperative scan to the position at the time of surgery. The distortion of interspinous regions is of particular importance in surgery for spinal instability such as occurs in trauma or spondylolisthesis. In addition, spinous process exposure, a necessary step for registration, limits the reduction in the size of the required incision. Shortcomings in 3D fluoroscopy include reductions in image quality for patients with osteopenia, obesity, or metallic implants. Also, one must factor in additional time during the initial learning phase. However, this diminishes once the surgeon gains experience with the new technology. Lastly, current devices only image a limited number of segments; thus for longer constructs, additional "spins" may be required. Regarding iMRI, its widespread adoption for use in treating spinal pathologies is limited, at present, by the high cost of the technology as well as concerns regarding any comparative advantage relative to endoscopic approaches or stereotactic neuronavigation with $\mathrm{CT}$ and preoperative MRI fusion. ${ }^{7}$ Further studies will be required to define the benefits of iMRI and the specific clinical advantages of the technology (such as during tumor resection) that will guide more widespread adoption. ${ }^{32}$

The numerous studies detailed herein frequently describe improved accuracy during placement of instrumentation relative to freehand or traditional fluoroscopy-based techniques; however, to date, no study has demonstrated significantly improved neurological outcomes in a headto-head comparison. Nevertheless, several comparative studies have worked to identify benefits of navigation that may correlate with outcomes. In a 2011 study, Wood and 
Mannion described increased positive neuromonitoring alarms as well as decreased accuracy with 2D-guided minimally invasive pedicle screw placement relative to $3 \mathrm{D}$ fluoroscopy, ${ }^{50}$ but the impact of these findings of outcomes remains unclear. A more recent paper demonstrated significantly improved overall screw accuracy and reduced operative time with $\mathrm{O}$-arm navigation in lumbar screw placement with the suggestion of improved outcomes as a benefit of this technique. ${ }^{13}$ Another study by von Jako et al. details the benefit of reduced radiation exposure using electromagnetic navigation for transpedicular screw fixation. ${ }^{47}$ While these factors, including improved accuracy, decreased radiation, and enhanced construct stability, may correlate with a better safety profile, further studies will be needed to demonstrate a definitive outcome benefit of MISS using navigation relative to conventional techniques.

\section{Future Direction}

The notion of coupling advanced image guidance and MISS is intuitive for allowing better surgical accuracy and reduced radiation exposure. More studies are needed, however, to better assess the efficacy and cost-effectiveness of these technologies. The future is promising, even beyond the current iCT/iMRI technology. One such area of exploration involves the use of a novel surgical robot system for percutaneous pedicle screw insertion. The BFRS consists of biplanar fluoroscopy, a surgical planning and operating system, and a robotic assist. Preliminary cadaveric studies suggest that the BFRS may be a useful adjunct to improve the accuracy of percutaneous pedicle screw placement. ${ }^{19}$ A Canadian group led by Sutherland reported their initial experience using the neuroArm navigation system with the ability to perform microneurosurgery with a robotic interface to improve accuracy. ${ }^{28}$ In the future, robotic applications may be feasible extensions in the management of spinal pathology via minimally invasive techniques or for microdiscectomy. Another emerging area involves the use of electromagnetic technology for image guidance. This technology bypasses many of the challenges of traditional navigation systems. In particular, the tracker and probe do not require a direct line of sight, allowing the surgical site to be moved readily without disrupting the surgical field or interfering with registration accuracy. And although this technology has primarily been used in cranial cases, the possibility remains that electromagnetic navigation could be useful in many facets of spinal surgery. ${ }^{9}$ Finally, radiation exposure remains an important consideration in MISS. A large number of the papers presented in this review describe decreased radiation exposure to the patient and surgeon using navigation relative to nonnavigated $2 \mathrm{D}$ fluoroscopic approaches during minimally invasive surgery. ${ }^{18,29,34-37,46}$ Preliminary studies suggest technologies such as cone-beam CT will improve visualization and guidance while decreasing cumulative intraoperative radiation exposure. ${ }^{34}$ Further refinements in imaging technology, including fusion to MRI and use of multimodality techniques including endoscopy for craniocervical junction pathologies, will continue to push the limits of MISS with the goal of improving the long-term radiation safety profile of these surgical adjuncts.

\section{Conclusions}

Refinements in image-guidance technologies and minimal access techniques have converged on spinal pathology, affording patients the ability to undergo safe, accurate operations without the associated morbidities of conventional approaches. While percutaneous transpedicular screw placement is among the most common procedures to benefit from navigation, other areas of spine surgery can benefit from advances in neuronavigation. As patients continue to demand these operations from their surgeons, and surgeons become increasingly aware of their utility, we anticipate further growth in the field of image-guided MISS.

\section{Disclosure}

Dr. Gokaslan reports direct stock ownership in US Spine and Spinal Kinetics and support of clinical or research efforts from AOSpine, AO North America, the Neurosurgery Research and Education Foundation, and DePuy.

Author contributions to the study and manuscript preparation include the following. Conception and design: Baaj, Moses, Mayer, Gokaslan. Acquisition of data: all authors. Analysis and interpretation of data: Baaj, Moses, Mayer, Kretzer, Wolinsky. Drafting the article: Baaj, Moses, Mayer, Strickland, Kretzer, Gokaslan. Critically revising the article: all authors. Reviewed submitted version of manuscript: Baaj, Moses, Mayer, Strickland. Approved the final version of the manuscript on behalf of all authors: Baaj. Study supervision: Baaj.

\section{References}

1. Allam Y, Silbermann J, Riese F, Greiner-Perth R: Computer tomography assessment of pedicle screw placement in thoracic spine: comparison between free hand and a generic 3Dbased navigation techniques. Eur Spine J 22:648-653, 2013

2. Baaj AA, Gokaslan ZL: Neuronavigation in spinal surgery. World Neurosurg 78:74-75, 2012

3. Dasenbrock HH, Clarke MJ, Bydon A, Sciubba DM, Witham TF, Gokaslan ZL, et al: Endoscopic image-guided transcervical odontoidectomy: outcomes of 15 patients with basilar invagination. Neurosurgery 70:351-360, 2012

4. Dhaliwal PP, Hurlbert RJ, Sutherland GS: Intraoperative magnetic resonance imaging and neuronavigation for transoral approaches to upper cervical pathology. World Neurosurg 78:164-169, 2012

5. Fessler RG, Khoo LT: Minimally invasive cervical microendoscopic foraminotomy: an initial clinical experience. Neurosurgery 51 (5 Suppl):S37-S45, 2002

6. Gelalis ID, Paschos NK, Pakos EE, Politis AN, Arnaoutoglou CM, Karageorgos AC, et al: Accuracy of pedicle screw placement: a systematic review of prospective in vivo studies comparing free hand, fluoroscopy guidance and navigation techniques. Eur Spine J 21:247-255, 2012

7. Grob D, Jeanneret B, Aebi M, Markwalder TM: Atlanto-axial fusion with transarticular screw fixation. J Bone Joint Surg Br 73:972-976, 1991

8. Han W, Gao ZL, Wang JC, Li YP, Peng X, Rui J, et al: Pedicle screw placement in the thoracic spine: a comparison study of computer-assisted navigation and conventional techniques. Orthopedics [epub ahead of print], 2010

9. Hayhurst C, Byrne P, Eldridge PR, Mallucci CL: Application of electromagnetic technology to neuronavigation: a revolution in image-guided neurosurgery. Technical note. J Neurosurg 111:1179-1184, 2009

10. Holly LT, Foley KT: Percutaneous placement of posterior cervical screws using three-dimensional fluoroscopy. Spine (Phila Pa 1976) 31:536-541, 2006 


\section{Z. B. Moses et al.}

11. Holly LT, Foley KT: Three-dimensional fluoroscopy-guided percutaneous thoracolumbar pedicle screw placement. Technical note. J Neurosurg 99 (3 Suppl):324-329, 2003

12. Hott JS, Papadopoulos SM, Theodore N, Dickman CA, Sonntag VKH: Intraoperative Iso-C C-arm navigation in cervical spinal surgery: review of the first 52 cases. Spine (Phila Pa 1976) 29:2856-2860, 2004

13. Houten JK, Nasser R, Baxi N: Clinical assessment of percutaneous lumbar pedicle screw placement using the $\mathrm{O}$-arm multidimensional surgical imaging system. Neurosurgery 70: 990-995, 2012

14. Hsu W, Kosztowski TA, Zaidi HA, Gokaslan ZL, Wolinsky JP: Image-guided, endoscopic, transcervical resection of cervical chordoma. Technical note. J Neurosurg Spine 12:431435,2010

15. Ishikawa Y, Kanemura T, Yoshida G, Ito Z, Muramoto A, Ohno S: Clinical accuracy of three-dimensional fluoroscopybased computer-assisted cervical pedicle screw placement: a retrospective comparative study of conventional versus computer-assisted cervical pedicle screw placement. Clinical article. J Neurosurg Spine 13:606-611, 2010

16. Kaibara T, Hurlbert RJ, Sutherland GR: Intraoperative magnetic resonance imaging-augmented transoral resection of axial disease. Neurosurg Focus 10(2):E4, 2001

17. Kakarla UK, Little AS, Chang SW, Sonntag VKH, Theodore $\mathrm{N}$ : Placement of percutaneous thoracic pedicle screws using neuronavigation. World Neurosurg 74:606-610, 2010

18. Kim JS, Eun SS, Prada N, Choi G, Lee SH: Modified transcorporeal anterior cervical microforaminotomy assisted by O-arm-based navigation: a technical case report. Eur Spine J 20 (Suppl 2):S147-S152, 2011

19. Kim S, Chung J, Yi BJ, Kim YS: An assistive image-guided surgical robot system using O-arm fluoroscopy for pedicle screw insertion: preliminary and cadaveric study. Neurosurgery 67:1757-1767, 2010

20. Kosmopoulos V, Schizas C: Pedicle screw placement accuracy: a meta-analysis. Spine (Phila Pa 1976) 32:E111-E120, 2007

21. Lee GY, Massicotte EM: Image-guided transsacral approach to presacral lesions of nerve root origin: technical note. Neurosurgery 57:E412, 2005

22. Leng LZ, Anand VK, Hartl R, Schwartz TH: Endonasal endoscopic resection of an os odontoideum to decompress the cervicomedullary junction: a minimal access surgical technique. Spine (Phila Pa 1976) 34:E139-E143, 2009

23. Luther N, Tomasino A, Parikh K, Härtl R: Neuronavigation in the minimally invasive presacral approach for lumbosacral fusion. Minim Invasive Neurosurg 52:196-200, 2009

24. Madawi AA, Casey AT, Solanki GA, Tuite G, Veres R, Crockard HA: Radiological and anatomical evaluation of the atlantoaxial transarticular screw fixation technique. J Neurosurg 86:961-968, 1997

25. Marawar S, Girardi FP, Sama AA, Ma Y, Gaber-Baylis LK, Besculides MC, et al: National trends in anterior cervical fusion procedures. Spine (Phila Pa 1976) 35:1454-1459, 2010

26. Nottmeier EW, Foy AB: Placement of C2 laminar screws using three-dimensional fluoroscopy-based image guidance. Eur Spine J 17:610-615, 2008

27. Nottmeier EW, Young PM: Image-guided placement of occipitocervical instrumentation using a reference arc attached to the headholder. Neurosurgery 66 (3 Suppl Operative): 138-142, 2010

28. Pandya S, Motkoski JW, Serrano-Almeida C, Greer AD, Latour I, Sutherland GR: Advancing neurosurgery with imageguided robotics. Technical note. J Neurosurg 111:1141-1149, 2009

29. Powell MF, DiNobile D, Reddy AS: C-arm fluoroscopic cone beam CT for guidance of minimally invasive spine interventions. Pain Physician 13:51-59, 2010
30. Rajasekaran S, Avadhani A, Shetty AP: Axial translaminar screw placement using three-dimensional fluoroscopy-based navigation. Singapore Med J 52:15-18, 2011

31. Rampersaud YR, Foley KT, Shen AC, Williams S, Solomito M: Radiation exposure to the spine surgeon during fluoroscopically assisted pedicle screw insertion. Spine (Phila Pa 1976) 25:2637-2645, 2000

32. Recinos PF, Benzel EC: Intraoperative magnetic resonance imaging, neuronavigation, and the transoral approach: considerations in adopting novel technologies to a standard surgical approach. World Neurosurg 78:71-73, 2012

33. Ruetten S, Komp M, Merk H, Godolias G: Full-endoscopic anterior decompression versus conventional anterior decompression and fusion in cervical disc herniations. Int Orthop 33:1677-1682, 2009

34. Schafer S, Nithiananthan S, Mirota DJ, Uneri A, Stayman JW, Zbijewski W, et al: Mobile C-arm cone-beam CT for guidance of spine surgery: image quality, radiation dose, and integration with interventional guidance. Med Phys 38:4563-4574, 2011

35. Scheufler KM, Cyron D, Dohmen H, Eckardt A: Less invasive surgical correction of adult degenerative scoliosis, part I: technique and radiographic results. Neurosurgery 67:696710,2010

36. Scheufler KM, Franke J, Eckardt A, Dohmen H: Accuracy of image-guided pedicle screw placement using intraoperative computed tomography-based navigation with automated referencing. Part II: thoracolumbar spine. Neurosurgery 69: 1307-1316, 2011

37. Schouten R, Lee R, Boyd M, Paquette S, Dvorak M, Kwon BK, et al: Intra-operative cone-beam CT (O-arm) and stereotactic navigation in acute spinal trauma surgery. J Clin Neurosci 19:1137-1143, 2012

38. Smith HE, Yuan PS, Sasso R, Papadopolous S, Vaccaro AR: An evaluation of image-guided technologies in the placement of percutaneous iliosacral screws. Spine (Phila Pa 1976) 31: 234-238, 2006

39. Summers LE, Kouri JG, Yang M, Jacob RP: Odontoid screw placement using Isocentric 3-dimensional C-arm fluoroscopy. J Spinal Disord Tech 21:45-48, 2008

40. Takahashi S, Morikawa S, Egawa M, Saruhashi Y, Matsusue Y: Magnetic resonance imaging-guided percutaneous fenestration of a cervical intradural cyst. Case report. J Neurosurg 99 (3 Suppl):313-315, 2003

41. Takahashi S, Morikawa S, Saruhashi Y, Matsusue Y, Kawakami M: Percutaneous transthoracic fenestration of an intramedullary neurenteric cyst in the thoracic spine with intraoperative magnetic resonance image navigation and thoracoscopy. Case report. J Neurosurg Spine 9:488-492, 2008

42. Takahashi S, Saruhashi Y, Odate S, Matsusue Y, Morikawa $\mathrm{S}$ : Percutaneous aspiration of spinal terminal ventricle cysts using real-time magnetic resonance imaging and navigation. Spine (Phila Pa 1976) 34:629-634, 2009

43. Tian W, Liu Y, Zheng S, Lv Y: Accuracy of lower cervical pedicle screw placement with assistance of distinct navigation systems: a human cadaveric study. Eur Spine J 22:148-155, 2013

44. Tormenti MJ, Kostov DB, Gardner PA, Kanter AS, Spiro RM, Okonkwo DO: Intraoperative computed tomography imageguided navigation for posterior thoracolumbar spinal instrumentation in spinal deformity surgery. Neurosurg Focus 28(3):E11, 2010

45. U1 Haque M, Shufflebarger HL, O'Brien M, Macagno A: Radiation exposure during pedicle screw placement in adolescent idiopathic scoliosis: is fluoroscopy safe? Spine (Phila Pa 1976) 31:2516-2520, 2006

46. Villavicencio AT, Burneikiene S, Bulsara KR, Thramann JJ: Intraoperative three-dimensional fluoroscopy-based comput- 
Neuronavigation in minimally invasive spine surgery

erized tomography guidance for percutaneous kyphoplasty. Neurosurg Focus 18(3): 3 , 2005

47. von Jako R, Finn MA, Yonemura KS, Araghi A, Khoo LT, Carrino JA, et al: Minimally invasive percutaneous transpedicular screw fixation: increased accuracy and reduced radiation exposure by means of a novel electromagnetic navigation system. Acta Neurochir (Wien) 153:589-596, 2011

48. Wang MY: Cervical crossing laminar screws: early clinical results and complications. Neurosurgery 61 (5 Suppl 2):311316,2007

49. Wolinsky JP, Sciubba DM, Suk I, Gokaslan ZL: Endoscopic image-guided odontoidectomy for decompression of basilar invagination via a standard anterior cervical approach. Technical note. J Neurosurg Spine 6:184-191, 2007

50. Wood M, Mannion R: A comparison of CT-based navigation techniques for minimally invasive lumbar pedicle screw placement. J Spinal Disord Tech 24:E1-E5, 2011
51. Yao N, Wang C, Wang W, Wang L: Full-endoscopic technique for anterior cervical discectomy and interbody fusion: 5-year follow-up results of 67 cases. Eur Spine J 20:899-904, 2011

52. Youkilis AS, Quint DJ, McGillicuddy JE, Papadopoulos SM: Stereotactic navigation for placement of pedicle screws in the thoracic spine. Neurosurgery 48:771-779, 2001

Manuscript submitted April 12, 2013.

Accepted May 28, 2013.

Please include this information when citing this paper: DOI: 10.3171/2013.5.FOCUS13150.

Address correspondence to: Ali A. Baaj, M.D., Division of Neurosurgery, The University of Arizona, Tuscon, AZ 85724. email: abaaj@surgery.arizona.edu. 